\title{
LA GESTION DE LA DIPUTACION PROVINCIAL DE SEGOVIA DURANTE LA DICTADURA DE PRIMO DE RIVERA *
}

\author{
POR \\ EnRiQue Orduña Rebollo
}

SUMARIO: I. INTRODUCCIÓN.-II. Sistuáción de LA DiputaCión de SEgovia en 1923.III. Actuación de la Diputación de Segovia en 1924: a) Beneficencia; b) Carreteras provinciales y caminos vecinales; c) Situación económica de la Diputación; d) Otros aspectos de la gestión provincial en 1924.-IV. ACTIVIDAD DE LA DIPUTACIÓN DE SEGOVIA 1925-1930: a) Beneficencia y sanidad; b) Obras públicas; c) Repoblación forestal; d) Otros aspectos de la actividad de la Diputación.-V. LA HACIENDA PROVINCIAL DE Segovia 1923-1930: a) La Hacienda provincial de 1920-1924; b) La Hacienda segoviana de 1925 a 1931.

\section{INTRODUCCION}

El interés despertado por los temas territoriales en las dos últimas décadas es una consecuencia de la evolución social del pueblo español, acompañada por la recuperación de las libertades públicas, que cristalizó en la democratización de las estructuras locales y en la consecución de cotas de autonomía probablemente no conocidas hasta ahora. Tales procesos suscitaron la búsqueda de identidades en los diversos estamentos territoriales, que cristalizaron en la celebración de Congresos y Reuniones de Historia Local.

Nuestra participación en alguno de ellos, nos llevó a tratar temas relacionados con la administración territorial, por lo que en esta ocasión vamos a considerar la situación de la Diputación Provincial de Segovia durante la dictadura de Primo de Rivera. Significando que esta colaboración tiene carácter complementario a la Ponencia del profesor Palomares, en análoga forma a la desarrollada en la primavera de este año con ocasión del II Congreso de Historia de Palencia (1). Por lo que estudiaremos diversos aspectos de la gestión de la Diputación, tales como su actitud en los primeros momentos de la Dictadura, los presupuestos, beneficencia, obras y servicios, carreteras, caminos, etc.

- Trabajo presentado al II Congreso de Historia de Segovia, noviembre 1989.

(1) Véanse PALOMARES IBÁÑEz, Jesús MARIA: La dictadura de Primo de Rivera en Palencia (1923-1930). ORDUÑA REBOLLO, ENRIQUE: La gestión de la Diputación de Palencia durante la Dictadura de Primo de Rivera, Palencia, Diputación Provincial (en prensa). 
Es preciso indicar una vez más, que el motor de la reforma local en el período de la Dictadura, don José Calvo Sotelo, albergaba el propósito de convertir en realidad los malogrados proyectos de régimen local elaborados por Maura en 1903 y 1907, introduciendo diversas modificaciones que se plasmaron en los Estatutos Municipal y Provincial, los cuales sin duda, contenian un reconocido perfeccionismo técnico y marcaron un impacto político decisivo en la administración local española. Lamentablemente el entorno político, carente de libertades públicas les hizo en gran medida inoperantes. Maura no concebía sus proyectos de ley al margen de un sistema democrático y fuera de un contexto de gran autonomía.

\section{SITUACION DE LA DIPUTACION DE SEGOVIA EN 1923}

La última Diputación Provincial segoviana, dentro de la legalidad constitucional , se constituyó el 3 de agosto de 1923, formada por los señores Abad, Alvarez, Arcinaga, Cáceres, Conde, Esteban Núñez, De Frías, García Junquero, González Ligero, Guajardo, Herrero Gil, Illera, Mesa García, Gilsanz, Suárez González, Torre Arocena, Torre, Carretero Vera, González Arranz y Angel Llorente Benito. Resultó elegido presidente el último de los citados, perteneciente al partido liberal, que contó con los votos de usus amigos liberales y conservadores», con el resultado de 18 a favor y dos en blanco (2).

La llegada de Primo de Rivera al poder y la constitución del Directorio Militar, en septiembre de 1923 , no supuso un impacto notable en la Diputación de Segovia, situación común a todas las Corporaciones provinciales de la región. El caso es que no se produjeron alteraciones ni casi alusiones en la Diputación segoviana a la nueva situación política, según se desprende de la revisión de los Libros de Actas de la Comisión, al menos en los primeros momentos. La más absoluta normalidad y continuidad presiden las sesiones de la Comisión de los días 13 y 28 de septiembre.

Pero en el curso de la última se detecta tempranamente la preocupación por el futuro de las Diputaciones Provinciales al tratar un tema presuntamente delicado como la «Asamblea de Diputaciones», reuniones periódicas de las mismas que se celebraban desde fines del siglo anterior. En la sesión se hizo mención a una carta circular de la Diputación de Soria, corporación convocante, para que la de Segovia:

(2) Véase Libro de Actas del Pleno. Diputación de Segovia (en lo sucesivo: LAPDS). Sesión del día 3 de agosto de 1923, fols. 33, 33 vto. y 34 . 
«pida al Directorio que se traduzcan en un Real Decreto las conclusiones de las Asambleas de Diputaciones celebradas en 1917 y 1921 y que no se haga ninguna reforma administrativa sin que sean oídas las Diputaciones y sin que las Cortes Constituyentes la voten» (3).

El acuerdo se aprobó por unanimidad, ampliándose en el sentido de que debía convocarse una nueva Asamblea de Diputaciones lo más brevemente posible, al objeto de ejercer mayor presión sobre el gobierno de la nación.

El Pleno de la Diputación de Segovia se reunió preceptivamente el 23 de octubre de 1923, bajo la presidencia del gobernador civil, el cual como presidente nato de la Corporación saludó a los reunidos, celebrando su buena disposición y deseos de trabajar por el interés común, tras la respuesta de cortesía del presidente, el gobernador se ausentó, dejando a los diputados reunidos para tratar asuntos de trámite y uno de gran interés: el documento dirigido al presidente del Directorio Militar sobre la Diputación y su futuro.

La Exposición al Directorio fue aprobada sin enmiendas ni rectificaciones. Uno de los ejemplares se depositó en la Secretaría General y el otro se remitió al gobernador civil para que fuese elevado al Directorio, y en caso de que la entrega se hiciese personalmente, solicitaron la posibilidad de que los redactores acompañasen a la autoridad gubernativa. Finalmente se tomó el acuerdo de agradecer corporativamente a los autores su esfuerzo, «por el brillante trabajo realizado, en el cual han sabido interpretar con toda fidelidad las aspiraciones de la Diputación» (4). No volvería a celebrarse ningún pleno hasta enero de 1924.

Los roces y dificultades iniciales de la Diputación Provincial de Segovia con el Directorio Militar fueron mínimos para el período inicial, salvo en las gestiones dedicadas a la defensa institucional de las Corporaciones provinciales, cuestión generalizada entre las demás Diputaciones. La revisión de los libros de actas nos depara una sensación de normalidad administrativa. No hay tampoco resistencia pasiva a las órdenes del gobernador, pero cuando surge una ocasión producida por un acto de autoridad, la Comisión invoca los preceptos legales que el Directorio no había podido derogar. Así se produjo cuando la Comisión informó al gobernador civil sobre el recurso de alzada interpuesto por el destituido secretario del

(3) Véase Libro de Actas de la Comisión Provincial. Diputación de Segovia (en lo sucesivo LACPDS). Sesión del dia 28 de septiembre de 1923, fols. 152 vto. y 153.

(4) Ibidem. 
Ayuntamiento de Vallelado, en el sentido de que para proceder a su destitución había que «atenerse a los preceptos del Real Decreto de 13 de junio de 1921» (5).

Es también importante consignar que la Diputación Provincial de Segovia disfrutaba de una saneada situación económica, como veremos después, coyuntura que no se producía en otros lugares. Las escasas deudas de la Diputación segoviana con el Estado se referían a Instrucción Pública, eran recientes y su pago había sido concertado en plazos fijos, incluso el Estado era deudor de la Diputación, por un anticipo que ésta hizo para financiar la construcción de la Cárcel Modelo de Madrid. Todas estas razones no obligaron a la Diputación de Segovia a elaborar un presupuesto extraordinario de gastos, que sin duda hubiese producido diferencias con las autoridades del Directorio.

\section{ACTUACION DE LA DIPUTACION DE SEGOVIA EN 1924}

La convulsión profunda en las Diputaciones Provinciales fue producida por el Real Decreto de 12 de enero de 1924 que ordenó la disolución de todas las Diputaciones de España con excepción de las de Alava, Guipúzcoa, Navarra y Vizcaya. También determinó que la designación de diputados provinciales se realizaría, a título interino, por los gobernadores civiles (6).

El mandato del artículo segundo del Real Decreto fue cumplido puntualmente por el gobernador civil de Segovia, general don Joaquín Serrano, que nombró a los Diputados, constituyéndose bajo su presidencia la Diputación Provincial el día 20 de enero de 1924 (7). Cumplimentadas las formalidades de rigor, el gobernador civil expresó que los únicos méritos para el cargo que ostentaba se cifraban en sus cuarenta y siete años de servicio a la patria y calificó a la Corporación de «asamblea de notables», cuyo amor al trabajo, honradez y desinterés, elogió ampliamente, indicando que su nombramiento se debía a la «ejecutoria que con vuestro saber y vuestro trabajo os habéis ganado» (8). Finalmente

(5) Véase LACPDS, Sesión del dia 2 de noviembre de 1923, fol. 168

(6) Véase Calvo Sotelo, J.: Mis servicios, op. cit., p. 22.

(7) Estaba formada por los siguientes señores: Mariano Larios, Pedro Quemada Romero, Mariano Cereceda Fernández, Fermín Rodríguez Fernández, Vicente Sanz Martin. Fernando Albertos Sanz, Manuel Garcia Arranz, Leopoldo Moreno Rodriguez, Juan García Segovia, Julián Rueda Benito. Tirso Rey González, Bonifacio Miguel Moreno, Pablo Fernández Marcos, Rodrigo Peñalosa Rivero. Andrés Marcos Callejo, Manuel Gómez García, Segundo Gila Sanz, Juan Gil Escorial, Valentín de Antonio Quijano y Julián Santos Blanco, en LAPDS. Sesión del dia 20 de enero de 1924, fols. 2 y 2 vto.

(8) Véase LAPDS, Sesión del día 20 de enero de 1924, fols. 8 y 8 vto. 
sería elegido presidente don Leopoldo Moreno Rodríguez por 19 votos a favor $y$ uno en blanco.

Asimismo el artículo sexto del RD, disponía que las Corporaciones Provinciales elevasen al Ministerio de la Gobernación en un plazo de quince días, prorrogado a treinta, una Memoria sucinta, detallando los defectos y anomalías que observasen en su funcionamiento, proponiendo las medidas necesarias para corregirlas (9).

En Segovia, la redacción de la Memoria corrió a cargo de la Comisión Provincial, en cuyo nombre el señor Gila, como vicepresidente de la misma, resumió los trabajos realizados y las informaciones practicadas, que en buena parte serían recogidas en el documento definitivo (10). Los funcionarios fueron objeto de elogio por su esfuerzo, competencia y asiduidad, pese a sus escasas retribuciones, por lo que debían ser atendidas las justas reivindicaciones y las mejoras que habían solicitado.

El Informe demostró un buen conocimiento de los diversos servicios que prestaba la Diputación y de su estado, principalmente los de beneficencia, carreteras y caminos vecinales. La valoración global era favorable en algunos casos y negativa en otros, y entre éstas, las más urgentes de reformar eran la maternidad, la lactancia y la observación de presuntos dementes. El estado de las vías provinciales no era bueno por su longitud y por la falta de recursos para atenderlas y la exigua retribución de los peones camineros.

Su diagnóstico sobre la Hacienda provincial fue positivo, y entre los proyectos futuros mencionó la instalación de una red telefónica provincial, que produjese la sensación «de que las Diputaciones sirven para algo más que para lo que han estado destinadas hasta ahora» (11). Propuso por último, que se incorporase al equipo redactor de la Memoria el presidente y vicepresidente de la Diputación para elaborar su versión definitiva. El Pleno hizo constar en acta un voto de gracias a la Comisión por el trabajo realizado, autorizándola para la redacción definitiva y posterior remisión al Ministerio de la Gobernación en los plazos legales.

La Memoria elevada a la superioridad por la Diputación Provincial de Segovia el 18 de febrero de 1924, contenía una visión realista

(9) Véase Anuario de la Vida Local, 1924. Administración Provincial: Mancomunidades, Diputaciones Provinciales y Cabildos Insulares. Madrid. Dirección General de Administración, 1925. tomo I. Esta disposición permitió a la Dirección General de Administración conocer la situación real de las Corporaciones y al reunir todas las Memorias en un tomo editado en 1925. nos ha permitido disponer de una valiosa información.

(10) Véase LAPDS, Sesión del dia 1 de febrero de 1924, fol. 19 vto.

(11) Ibidem, fol. 20 vio. 
de la situación de la Corporación y de los problemas que tradicionalmente soportaba. Estos aun siendo graves no alcanzaban el tono dramático descrito en otras Memorias, sobre todo respecto a los Centros Asistenciales y Benéficos.

Señalaban los diputados segovianos en su informe las tres ligaduras que oprimían a la Corporación impidiéndola su desarrollo natural: la dificultad en el cobro del contingente provincial, las cantidades que estaban obligados a satisfacer por gastos de Instrucción Pública dependientes del Estado, que ni creó, ni inspeccionaba, no regía y la importancia de la red de carreteras y caminos vecinales, construidos por la Diputación.

Los nuevos diputados elogiaron la administración de sus antecesores y la parquedad en los gastos de las Corporaciones anteriores. Esta aclaración no debe extrañar, pues las "notas oficiosas» reiteraban el propósito de limpiar la corrupción de los Ayuntamientos y Diputaciones. Criterio que se traducía en una gran desconfianza por parte de los delegados gubernativos en las Corporaciones locales. Pero en la mayoría de las ocasiones resultaron infundadas tales presunciones y respecto a los casos estudiados por nosotros siempre se mencionó la «honradez de las Corporaciones anteriores» y no hemos detectado irregularidades reflejadas en los libros de actas.

La Diputación segoviana en 1924 no tenía más deudas con el Estado que las de Enseñanza antes mencionadas, y habia concertado su abono en ocho anualidades. Existía otra, de menor cuantía, con los maestros por el aumento gradual de retribuciones, también convenido su pago en plazos fijos. Los gastos siempre estaban hechos previo acuerdo razonado, justificados y realizados los pagos, de "rayana en la tacañería» calificaron el criterio que primó en las Corporaciones anteriores al realizar los gastos, pues incluso de la partida de imprevistos, dotada con 15.000 pesetas para 1923, aún no se había consumido la mitad en febrero de 1924 (12).

La Memoria de la Diputación segoviana aporta datos sobre su personal que no son frecuentes en las de otras provincias, detallando la plantilla, por categorías, retribuciones, etc. Estimaba al personal, suficiente e incluso podría reducirse en un 20 por 100 descrito como muy competente, recogía la información facilitada al Pleno por el señor Gila, referente a la parquedad de sus retribuciones y la inferioridad económica manifiesta respecto a otros centros

(12) Véase Anuario..., op. cit., p. 332. Téngase en cuenta que se referían a los gastos del ejercicio anterior de 1923. 
del sector público o privado, pues incluso, en algunos casos, los empleados se encontraban por debajo del nivel salarial de los jornaleros (13).

\section{a) Beneficencia}

La Diputación subvencionaba a diversas instituciones benéficas de la ciudad, costeaba baños medicinales en el Balneario Segoviano a 60 enfermos todos los años, sufragaba la estancia de los dementes en otros manicomios y aportaba al Hospital de la Misericordia de Segovia, 16.000 pesetas anuales por estancias de enfermos, cantidad que preveía incrementar por las reformas $y$ mejoras introducidas en dicho centro hospitalario, que era de fundación particular y sometido al patronato del obispo (14).

Los servicios sostenidos en exclusiva por la Diputación eran: la Casa de Misericordia, Expósitos, Maternidad, Huérfanos y Desamparados de Segovia. Concentrados todos en un mismo recinto, aunque en distintos pabellones, el total de acogidos en dichos servicios en 1924 ascendía a 517 y consumían la partida de mayor cuantía consignada en el Presupuesto para Beneficencia (15).

La atención, encomendada a las Hijas de la Caridad de San Vicente de Paúl, era alabada por su gestión inteligente y eficaz, notable en cuanto a calidad de la alimentación, vestuario, régimen interior y educación. Eran más críticos con la enseñanza en escuela y talleres, pues sin resultar defectuosa del todo, estaba deficientemente dotada de medios personales y técnicos, y requería su modernización, intensificación y ampliación a las especialidades de hojalatería y sillería para los niños y enseñanza doméstica y arte culinario para las niñas (16).

Sin embargo la situación era inferior en la sección de lactancia, pese a que en los tres últimos años se redujo la mortalidad infantil al 38,98 por 100 (17). Esta situación tenía su causa principal en las taras orgánicas y las enfermedades heredadas, como la sífilis, dolencia que aquejaba a los expósitos, con el agravante de que éstos contagiaban su peligrosa enfermedad a las amas de cría. Los redactores de la Memoria, señalaron la necesidad de dotar a los servicios de un sistema de investigación serológica que permitiese

(13) Ibidem, pp. 332 y 333

(14) Véase PALOMARES IBÁÑEZ,J. M.: La Condición Obrera y las Asociaciones en la ciudad de Segovia durante la Restauración, Segovia, 1989, fol. 8 (inédito).

(15) En el Presupuesto de 1923: 278.383 pesetas de un total de 363.043 , lo que suponía el 76 por 100 del capitulo completo.

(16) Véase Anuario..., op. cit., p. 334.

(17) En el caso de Palencia el 62 por 100 para los niños menores de dos años. En: Anuario..., op. cit., p. 271. 
la exploración de todos los ingresados. Los cuales eran encomendados en su mayoría a nodrizas externas, en tanto no se crease una sección de Puericultura.

Respecto al manicomio, por aquellas fechas de reciente construcción, era un pabellón de observación de presuntos alienados, cuyo régimen estaba «poco en consonancia con los principios de la ciencia psiquiátrica actual» (18), pues al parecer los internos superaban los plazos de estancia marcados por la ley y eran tratados con excesivo rigor.

La localización de todos los servicios en un mismo complejo, reclamaba la necesidad de construir otros nuevos o ampliar los existentes, entre ellos un asilo de ancianas, pues sólo acogían a los varones, y otro para los impedidos por lesiones o dolencias incurables no contagiosas. La situación más grave se producía en la sección de Maternidad, instalada en una habitación pequeña, y sin ventilación, en la que además de estar juntas las embarazadas y las puérperas, se realizaban los partos a la vista de unas y otras. Esta grave situación debía remediarse, aportando dos soluciones: construir un nuevo pabellón o modificar el convenio existente con el Patronato del Hospital presidido por el obispo, para canalizar hacia dicho centro todos los ingresos de la sección de maternidad, cuyo promedio anual era de 18 a 19 acogidas (19).

\section{b) Carreteras provinciales y caminos vecinales}

En 1924, la red construida y conservada por la Diputación de Segovia era de 215 y 345 kilómetros, respectivamente. Estas dimensiones, situaban a la Corporación segoviana entre las primeras por la titularidad de la extensa red provincial y por el esfuerzo de su mantenimiento. En aquel momento estaban en construcción tres caminos vecinales con un total de 12 kilómetros $y$ en reparación 33 kilómetros de carreteras, ambas obras para un plazo de tres años. En general el estado de las vías provinciales era malo e inadecuado para el tráfico automovilístico (20).

La causas del mal estado de las carreteras se atribuían en primer lugar a que en los ejercicios anteriores las cantidades dedicadas a conservación habían sido mínimas. La segunda causa era la escasa remuneración de los peones camineros $(1,75$ pesetas diarias hasta $1920 ; 2,25$ en 1923 y 2,75 en 1924), por lo que debian buscar un complemento a sus ingresos realizando otros trabajos,

(18) Ibidem, p. 335

(19) Ibidem, p. 334

(20) Ibidem, p. 336. 
sobre todo labores agrícolas en tiempo de la recolección, razón por la que no cuidaban de forma permanente las carreteras. Al coincidir las elevadas temperaturas del verano con la mayor época de su absentismo laboral, el calor agrietaba el pavimento formando baches que al llegar la época de las lluvias deterioraba irremediablemente la carretera. La última razón era la carencia de maquinaria moderna e idónea, para construir y conservar las carreteras y caminos, y sólo disponer de herramientas obsoletas, manuales o movidas por tracción animal (21). Ante panorama tan poco halagüeño, los redactores de la Memoria proponían soluciones inmediatas (22).

\section{c) Situación económica de la Diputación}

La economía de la Diputación de Segovia era, como hemos indicado, bastante próspera, pues todos los años saldaba su presupuesto con superávit y sus deudas con el Estado estaban perfectamente atendidas.

Según leemos en la Memoria el repartimiento entre los pueblos era el más importante y casi único recurso provincial, aunque en la práctica suponía un gravamen que pesaba sobre los presupuestos municipales. En consecuencia pedian la supresión de este contingente y la búsqueda de fórmulas análogas a los Conciertos Económicas, o en su defecto la facultad para imponer arbitrios sobre obras y servicios costeados con sus fondos, sobre el capital de sociedades anónimas, comanditarias y bancos, industrias extractivas y otros signos de riqueza, también podía optarse por girar un repartimiento sobre las contribuciones directas (23).

\section{d) Otros aspectos de la gestión provincial en 1924}

Completaba la exposición de la situación provincial y sus deficiencias, el deseo de establecer una red telefónica provincial que permitiese la intercomunicación entre los diversos municipios y la capital. Otro objetivo era la creación de becas para cursar estudios superiores artísticos, científicos y literarios, financiar los estudios de capataces agrícolas y especialistas agrarios, en tanto no se dispusiese de una Granja Agrícola en Segovia. Incluían la protección del patrimonio artístico con la elaboración de un inventa-

(21) Ibidem, p. 337.

(22) Esta consistia en: mayor consignación para reparaciones del firme, incremento de la remuneración a todo el personal afecto al servicio, adquisición de maquinaria moderna $y$ reducción de la plantilla fija de peones camineros, contratando personal en épocas concretas y para obras determinadas, al tiempo que indicaban la necesidad de crear una plaza de Ayudante de Obras Públicas, que colaborase con el ingeniero, descargándole de trabajos burocráticos.

(23) Ibidem, p. 338. 
rio real y un programa para la conservación de los importantes monumentos existentes en la provincia, complementado con la defensa de las costumbres locales y organización del turismo, apoyando todas estas actividades con una biblioteca provincial moderna y accesible para los usuarios. Preveían la organización de la enseñanza agrícola, exposiciones agrarias provinciales y cuanto contribuyese en pro de una verdadera política de fomento provincial. Por último proponían construir, de acuerdo con el Estado y con las provincias limítrofes, líneas ferroviarias que facilitasen las comunicaciones y complementasen la escasa red ferroviaria provincial, pues sólo la línea del Norte transcurrida por una pequeña porción de su territorio (24).

\section{ACTIVIDAD DE LA DIPUTACION DE SEGOVIA 1925-1930}

El Estatuto Provincial de 20 de marzo de 1925, incorporó las provincias a la obra legal del señor Calvo Sotelo, y marcó, sin duda, un hito fundamental en la administración de las mismas, pues rompió, al menos sobre el papel, con la dependencia gubernamental que figuraba en la legislación del siglo XIX incluida la entonces vigente de 1882. Como el profesor García de Enterría afirma: «la aportación más indiscutible del EP al Derecho fue sin duda la verdadera aparición de la provincia como entidad local») (25), pues es sabido que tal figura territorial había sido un organismo de la administración periférica del Estado, a las órdenes del gobernador civil, fiel correa transmisora del caciquismo. El Estatuto rompe estas viejas funciones, e invierte la situación: los Ayuntamientos agrupados constituyen la provincia y en virtud del sistema de Carta Intermunicipal podían asociarse rebasando los límites del territorio provincial. Igualmente ampliaba las funciones y competencias provinciales.

Sin embargo la experiencia demostró muy pronto que los medios eran insuficientes para renovar la vida local española (26). Aunque siempre hemos pensado que tampoco existía voluntad política de impulsar la reforma, que por otro lado, fue avanzadilla de otras iniciadas posteriormente, sin ir más lejos la cooperación de las Diputaciones con los Ayuntamientos, eje básico de la actual reforma local española.

(24) Ibidem, p. 332.

(25) Véase DiEz GARCíA DE ENTERRIA E.: "La provincia en el Régimen local español», en Problemas actuales de Régimen Local, segunda edición, Sevilla. Universidad, 1986, p. 36.

(26) Véase DíEZ GONZÁLEZ,F.: "La provincia eje de una política para la vida local», en Memoria de la Gestión Corporativa de la Excma. Diputación Provincial de León, 1953. León, 1954, 25 páginas. 
El título III, capítulo I del EP describía minuciosamente el procedimiento de elección de los diputados provinciales, peró nunca entró en vigor, pues la Disposición final del mismo texto, ordenaba la constitución de las Diputaciones Provinciales el 1 de abril, "con las personas que los gobernadores civiles designen», y aunque el Libro primero del Estatuto entró en vigor, las elecciones se pospusieron a la realización de un nuevo censo electoral. La promulgación y vigencia del Estatuto supuso el nombramiento gubernativo de una nueva Corporación Provincial (27).

A partir de entonces la Diputación de Segovia aumentó su actividad como apreciamos en los libros de actas de la Comisión Provincial Permanente que nos facilita una idea muy concreta del volumen de dicho incremento, relacionado sin duda con la mejora de la Hacienda Provincial.

Como muestra de este dinamismo basta enunciar los asuntos que con más frecuencia fueron objeto de discusión y toma de decisión por la Comisión, entre ellos:

Beneficencia, instalaciones eléctricas, agrupación de Ayuntamientos, baños, pastoreo abusivo, biblioteca provincial, caminos vecinales, carreteras provinciales, Instituto Provincial de Higiene, repoblación forestal, ferrocarriles, etcétera.

La carencia de espacio nos impide hacer un minucioso análisis de cada cuestión, pero no queremos desaprovechar la oportunidad para realizar algunas consideraciones sobre aspectos concretos.

\section{a) Beneficencia y sanidad}

La situación de estos servicios se encuentra reflejada en la Memoria de febrero de 1924, y ciertamente había mejorado respecto a 1920, mejoría que se confirmará durante el año, según los datos sobre mortalidad que se reflejan a fines de febrero de 1925, conforme la estadística de la Corporación nombrada en enero del año anterior (28).

(27) Véase LAPDS, Sesión del 1 de abril de 1925, fols. 1 y 1 vto. La Diputación se constituyó preceptivamente el día 1 de abril, siendo elegido presidente Segundo Gila. Los diputados designados fueron: Segundo Gila, Mariano Larios, Andrés Marcos Callejo, Julián Santos Blanco y Juan Gil Escorial; como diputados directos titulares y como diputados corporativos: Modesto Fraile Gómez, Tomás de Angulo de Blas, Alfedro Bahillo González, Feliciano Blánquez Gutiérrez, Manuel Gómez García y Valentín Cardiel Merino. Tres días más tarde lo hizo la Comisión Provincial Permanente, en cuya sesión se formaron las Comisiones y designaron sus componentes. Véase LACPDS, Sesión del 4 de abril de 1925 , fols. 95 a 96.

(28) Véase LACPDS, Sesión del día 28 de febrero de 1925, fols. 72 y 72 vto. 


\section{ESTADISTICAS DE MORTALIDAD EN CENTROS BENEFICOS}

\begin{tabular}{|c|c|c|c|c|c|c|c|c|c|c|}
\hline \multirow{2}{*}{ Secciones } & \multicolumn{2}{|c|}{1920} & \multicolumn{2}{|c|}{1921} & \multicolumn{2}{|c|}{1922} & \multicolumn{2}{|c|}{1923} & \multicolumn{2}{|c|}{1924} \\
\hline & Núm. & $\begin{array}{c}\text { Porcen- } \\
\text { taje }\end{array}$ & Núm. & \begin{tabular}{|} 
Porcen- \\
taje
\end{tabular} & Núm. & $\begin{array}{c}\text { Porcen- } \\
\text { taje }\end{array} \mid$ & Núm. & 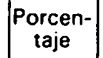 & Núm. & $\begin{array}{c}\text { Porcen- } \\
\text { taje }\end{array}$ \\
\hline $\begin{array}{l}\text { Lactancia } \ldots . \\
\text { Párvulos .... } \\
\text { Adolescentes } \\
\text { Maternidad ... } \\
\text { Ancianos .... } \\
\text { Alienados ... }\end{array}$ & $\begin{array}{r}101 \\
208 \\
286 \\
26 \\
25 \\
27\end{array}$ & $\begin{array}{r}65,34 \\
5,76 \\
3,49 \\
0 \\
16,00 \\
18,51\end{array}$ & $\begin{array}{r}114 \\
178 \\
291 \\
15 \\
25 \\
29\end{array}$ & $\mid \begin{array}{r}43,35 \\
2,81 \\
1,37 \\
0 \\
16,00 \\
31,00\end{array}$ & $\begin{array}{r}86 \\
147 \\
285 \\
18 \\
25 \\
30\end{array}$ & $\left|\begin{array}{r}40,62 \\
3,40 \\
0 \\
0 \\
20,00 \\
26,66\end{array}\right|$ & $\begin{array}{r}202 \\
151 \\
281 \\
20 \\
25 \\
26\end{array}$ & $\begin{array}{r}34,30 \\
3,31 \\
1,00 \\
0 \\
24,00 \\
34,62\end{array}$ & $\begin{array}{r}97 \\
120 \\
283 \\
26 \\
25 \\
27\end{array}$ & $\begin{array}{r}14 \\
7 \\
7 \\
4 \\
12 \\
26\end{array}$ \\
\hline
\end{tabular}

La maternidad era el gran desafío pendiente de los servicios de Beneficencia; por ello en el curso de los años 24 y 25 se construyó un nuevo.departamento de Maternidad, que a fines de 1925 estaba a punto de inaugurarse. Con tal ocasión se presentaron a la Comisión Provincial las bases para su buen funcionamiento, articulados en un Reglamento redactado por el señor Gila, diferente del que existía hasta entonces por «su ideología progresiva, a la que de antiguo predominaba en la apreciación de los problemas benéficosociales y los rumbos cada vez más cristianamente democráticos, que es preciso imprimir a todas las colectividades agrupadas al calor de la Beneficencia» (29).

En efecto, el nuevo Reglamento, acorde con las instalaciones que funcionaron a partir del 1 de enero de 1926, tenía marcadas diferencias con el antiguo:

«... la ampliación del aislamiento a toda mujer necesitada por razones médicas y de orden social de los auxilios que la maternidad pueda prestarla; la permanencia de las puérperas en el Departamento varias semanas después del parto, hasta que puedan reintegrarse a su vida social completamente restablecidas en su salud; el estímulo de los sentimientos maternales por medio de la permanencia del hijo al lado de la madre y confiado a su lactancia y cuidado durante algunas semanas; el establecimiento obligatorio de la estancia de las embarazadas al aire libre durante varias horas al día...» (30).

El artículo 128 del EP, disponía que en cada provincia se crease un Instituto de Higiene; en Segovia se cumplimentó lo ordenado, incorporándose la Brigada Sanitaria. Fueron numerosas las ocasio-

(29) Véase LACPDS. Sesión del día 22 de diciembre de 1925. fol. 25 vto.

(30) lbidem, fol. 96. 
nes que se reflejan en el Libro de Actas incidencias del nuevo organismo, como la reclamación al Ayuntamiento de la capital de 1.500 pesetas, que la Corporación municipal adeudaba a la extinguida Brigada Sanitaria y que según sus alegaciones, el municipio segoviano no abonaba en virtud de un Convenio con el Gobierno Civil, por el que cedia un local para dicha Brigada y el personal de laboratorio preciso (31).

Finalmente se aceptó para el ejercicio 1925-26 la renta de 1.500 pesetas por los locales requiriéndose al Ayuntamiento de Segovia.

«... para que manifieste si opta por contribuir con el 1 por 100 de su presupuesto total de ingresos para el sostenimiento del Instituto Provincial de Higiene y Sanidad, con derecho, como es consiguiente, a todos los servicios del mismo dentro de su municipalidad, o si por el contrario opta por la creación y sostenimiento de un Laboratorio y servicios de desinfección con carácter exclusivamente municipal...» (32).

\section{b) Obras públicas}

La construcción y reparación de carreteras provinciales y caminos vecinales, ocupó en todas las sesiones de la Comisión Provincial un apartado. Basta saber que desde 1925 se repararon y construyeron nuevos caminos y carreteras, lo que produjo la existencia de una verdadera multitud de expedientes sobre la materia, en los que participó a veces el Estado por medio de subvenciones, aportaciones del Circuito de Firmes Especiales, etc. En otras ocasiones se realizaron a expensas de la propia Corporación o con la cooperación de las Diputaciones limítrofes. A veces se limitaban a informes sobre cuestiones que afectaban a la provincia de Segovia, como el caso de las autovías Irún-Madrid o La Coruña-Madrid, proyectos que discurrían por una parte importante del territorio segoviano.

Habiamos mencionado anteriormente la dificiencia del material y equipo del servicio. A partir de 1925 se tratarán de resolver estas carencias con la adquisición de nueva maquinaria para la sección de vías y obras (33).

En materia de ferrocarriles fueron dos los objetivos de la Diputación segoviana. Por un lado, la prolongación de la línea

(31) Véase LACPDS, Sesión del día 19 de agosto de 1925, fol. 188.

(32) Ibidem, fol. 188 vto.

(33) Véase LACPDS, Sesión del día 5 de septiembre de 1928, fol. 116. 
eléctrica del puerto de Navacerrada a Segovia (34). La otra reivindicación ferroviaria, que no pasó de un intercambio de opiniones con el presidente de la Diputación de Burgos, consistió en proyectar un ferrocarril que comunicase las dos capitales de provincia por Aranda de Duero y enlazar con las líneas de Ariza y del Norte.

\section{c) Repoblación forestal}

La política de la Dictadura primorriverista, tratando de poner en práctica aspectos parciales regeneracionistas, cifró en la repoblación forestal uno de los pilares del resurgimiento económico nacional. Ante tal perspectiva la Diputación de Segovia solicitó establecer un vivero central de pinos silvestres que facilitaría semillas y plantas a particulares y Corporaciones para cooperar eficazmente a la repoblación del arbolado. Requirió también, por medio del Boletín Oficial de la Provincia, a los Ayuntamientos para que ofrecieran terrenos adecuados y establecer el vivero central (35). Posteriormente se realizaron varios intentos, que tuvieron mejor fortuna, para repoblar la vertiente norte de la cordillera, afectando a los municipios de El Espinar, Otero de Herreros, Ortigosa del Monte, La Losa y Revenga (36).

Las preocupaciones forestales de la Diputación segoviana no se limitaron exclusivamente a la repoblación, sino que afectaron a la introducción de nuevas técnicas y explotaciones. En este sentido, señalar la plantación de 10.000 moreras en los viveros de la Corporación con el propósito de facilitar alimentos a la industria de la seda (37).

\section{d) Otros aspectos de la actividad de la Diputación}

Entre los diversos asuntos revisados, hemos seleccionado alguno de interés local, como el himno de Segovia (38).

En un contexto político, la Diputación participó en la Asamblea de Uniones Patrióticas, celebrada en Medina del Campo, y en el

(34) Véase LACPDS, Sesión del día 14 de noviembre de 1927, fol. 67 vto.

(35) Véase LACPDS, Sesión del día 18 de enero de 1926, fol. 121.

(36) Véase LACPDS, Sesiones de los dias 13 de octubre de 1926, fols. 155 y 155 vto.; 23 de abril de 1928, fols. 8 y 8 vto., y 28 de mayo de 1928, fols. 33 y 33 vto.

(37) Véase LACPDS, Sesión del día 28 de mayo de 1928, fol. 36.

(38) Véase LACPDS, Sesión del día 11 de junio de 1928, fol. 48 vto. Fueron autores de la partitura y de la letra don Luis Martín Garcia Marcos y don Carlos Martín Crespo, respectivamente. Cantado por primera vez en la ciudad el día 3 de junio de 1982, la Diputación felicitó a los autores calurosamente por el éxito obtenido y la Comisión la remitió a los establecimientos de Beneficencia para que ensayase la Banda de Música y fuese cantado por los niños acogidos en todas las solemnidades. 
simultáneo homenaje de todas las Diputaciones de la región a Primo de Rivera, con el descubrimiento de una lápida en el castillo de la Mota, ensalzando al dictador (39).

Con criterios más económicos comprobamos el interés en asistir al Primer Congreso Nacional Cerealista, que se celebró en Valladolid del 25 de septiembre al 5 de octubre de 1927, y en el que participó la Diputación como congresista titular (40). Los intereses agrarios remolacheros fueron defendidos, en 1925, ante la posibilidad de que el Gobierno importase azúcar de Cuba, "cuyo hecho produciría enormes perjuicios a la economía nacional», según denunció el presidente de la Diputación de Valladolid, en telegrama dirigido al de Segovia, acordando dirigirse a Primo de Rivera en solicitud de una información para oír los intereses contrapuestos a. la mencionada importación de azúcar (41).

\section{LA HACIENDA PROVINCIAL DE SEGOVIA 1923-1930}

La gestión del período no puede desvincularse de la Hacienda expresada en los presupuestos del decenio en dos fases: desde 1920 hasta la entrada en vigor del Estatuto Provincial y desde 1926 a 1931. Se justifica plenamente esta censura, pues en materia presupuestaria existe una continuidad hasta 1924, incluso después del golpe militar y disolverse la Diputación. Mientras que, a partir de 1926, advertimos un cambio radical en la elaboración del presupuesto y una nueva concepción de partidas y capítulos (42).

\section{a) La Hacienda Provincial de 1920-1924}

La Diputación de Segovia tenía un presupuesto de ingresos entre los años 1919 y 1924 que oscilaba entre 1.504.739,76 pesetas, para el primero de los años citados, y 2.597.730,73, para 1924. Respecto a los gastos, en 1919 se presupuestaron $1.205 .543,36$, y en 1924, 1.770.201,75. En consecuencia el superávit, que sería permanente a lo largo de la década, en 1919 fue de $299.196,20$, y en 1924 , de $827.528,98$ pesetas.

(39) Véase LACPDS, Sesión del dia 18 de mayo de 1927, fol. 122

(40) Véase LACPDS, Sesión del día 7 de septiembre de 1927, fols. 2 y 13

(41) Véase LACPDS, Sesión del dia 18 de noviembre de 1925, fols. 65 y 65 vto.

(42) Hemos utilizado para la realización de este epígrafe los Presupuestos Provinciales de la Diputación de Segovia, existentes en su Archivo y que corresponden a los ejercicios: 1919. 1922-23, 1923-24, 1924-25, 1925-26, 1927, 1928, 1929, 1930 y 1931. 


\section{PRESUPUESTO DE INGRESOS Y GASTOS 1920-1924}

\begin{tabular}{|c|c|c|c|}
\hline Años & Ingresos & Gastos & Superávit \\
\hline $\begin{array}{l}1919 \\
1922 \\
1923 \\
1924\end{array}$ & $\begin{array}{l}1.504 .739,76 \\
2.262 .056,10 \\
2.540 .693,95 \\
2.597 .730 .73\end{array}$ & $\begin{array}{l}1.205 .543,36 \\
1.683 .741,25 \\
1.653 .371,10 \\
1.770 .201,75\end{array}$ & $\begin{array}{l}229.196,20 \\
578.314,76 \\
887.322,85 \\
827.528,98(43)\end{array}$ \\
\hline
\end{tabular}

Es evidente que la situación de la Hacienda Provincial segoviana estaba saneada. Comparando con el caso de Palencia, estudiado recientemente, nos encontramos para 1924 las $879.286,33$ pesetas del presupuesto de ingresos de la Diputación palentina, con los 2.597.730,73 de Segovia, que suponen prácticamente tres veces más. Si consideramos el módulo pesetas/habitante, según el censo de 1920 , tenemos 4,57 pesetas/habitante para Palencia y 15,96 pesetas/habitante en el caso de Segovia (44).

Los ingresos, como ya sabemos, correspondian básicamente al capítulo Repartimientos entre los pueblos, que supuso para 1924 el 42 por 100 sobre el total del presupuesto. Otro elemento presupuestario muy importante eran las Resultas, cantidades pendientes de cobrar, pertenecientes en la práctica al capítulo de Repartimientos, consignado en los apéndices de los presupuestos y que pasaban de un ejercicio a otro sin que los Ayuntamientos deudores pudiesen satisfacerlas. El cuadro siguiente es significativo para conocer la procedencia de los ingresos provinciales por Repartimientos y Resultas y su porcentaje sobre el total del presupuesto de ingresos:

\section{PROCEDENCIA DE LOS INGRESOS PROVINCIALES}

\begin{tabular}{|c|c|c|c|}
\hline Años & Repartimientos & Resultas & Porcentaje sobre total \\
\hline $\begin{array}{l}1919 \ldots \\
1922 \ldots \\
1923 \\
1924 \ldots\end{array}$ & $\begin{array}{r}643.828,50 \\
908.176,86 \\
978.869,04 \\
1.067 .193,04\end{array}$ & $\begin{array}{r}762.729,70 \\
1.035 .874,54 \\
1.452 .381,11 \\
1.430 .821,13\end{array}$ & $\begin{array}{l}93 \\
86 \\
95 \\
96(45)\end{array}$ \\
\hline
\end{tabular}

El resto de las partidas eran de menor cuantía, oscilando entre las $24.206,56$ pesetas de 1922 y las $24.956,56$ de 1924 , o la de

(43) Véase Presupuestos Provinciales. Años 1919, 1922-23, 1923-24, y 1924-25. A los efectos de nuestro trabajo no es trascendente la ausencia de los años 1920 y 1921 . Elaboración propia.

(44) Véase Población de hecho de los municipios españoles según los censos oficiales de 1900 a 1981, INE, Madrid, 1987.

(45) Véase Presupuestos..., op. cit., elaboración propia. 
arbitrios, con 9.860 y 2.260 para igual periodo. Los porcentajes de los diversos capítulos del presupuesto en 1924 eran:

\begin{tabular}{|c|c|c|c|}
\hline \multicolumn{2}{|l|}{ I NGRESOS } & \multicolumn{2}{|l|}{ GAStOS } \\
\hline & Porcentaje & & Porcentaje \\
\hline $\begin{array}{l}\text { Repartimientos } \\
\text { Beneficencia } \ldots \\
\text { Arbitrios } \ldots \ldots \ldots \\
\text { Resultas } \ldots \ldots \ldots \\
\text { Reintegros } \ldots \ldots\end{array}$ & $\begin{array}{r}41,08 \\
0,96 \\
0,08 \\
55,08 \\
2,80\end{array}$ & 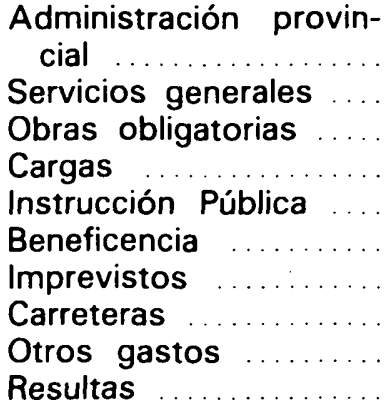 & $\begin{array}{r}6,02 \\
0,90 \\
16,60 \\
7,22 \\
7,85 \\
25,03 \\
0,67 \\
8,80 \\
2,99 \\
23,92(46)\end{array}$ \\
\hline
\end{tabular}

Los Caminos, la Beneficencia y las Resultas eran los conceptos con mayor incidencia en el presupuesto de gastos, sin olvidar los de Instrucción, correspondientes a servicios creados por el Estado. Su distribución para los años estimados es como refleja el siguiente cuadro:

\begin{tabular}{|c|c|c|c|c|}
\hline Años & Caminos & Instrucción & Beneficencia & Resultas \\
\hline $\begin{array}{l}1919 \\
1922 \\
1923 \\
1924\end{array}$ & $\begin{array}{l}112.500,00 \\
422.185,55 \\
250.307,50 \\
275.000,00\end{array}$ & $\begin{array}{l}141.037 \\
182.550 \\
138.637 \\
138.967\end{array}$ & $\begin{array}{l}303.903,30 \\
363.043,50 \\
391.812,25 \\
443.097,25\end{array}$ & $\begin{array}{l}428.171,46 \\
419.929,46 \\
527.650,27 \\
423.510,24(47)\end{array}$ \\
\hline
\end{tabular}

Todo lo anterior certifica el estado de la Hacienda Provincial, sin olvidar que en el caso de Segovia los superávit eran relativamente ficticios, pues no olvidemos que al año siguiente aparecían incorporados al capítulo de Resultas que, como hemos visto, unas veces se cobraban y otras no. Quizá esta fuese la razón que impedía a los diputados provinciales de Segovia, abordar obras de envergadura, pues con el mantenimiento de los servicios generales, la beneficencia y los caminos y carreteras, se agotaba prácticamente el numerario; habría que añadir el temor al endeudamiento y el sentido de la responsabilidad, cualidades muy marcadas en el carácter segoviano.

(46) Véase Presupuesto provincial para el año 1925, Segovia., Imp. Provincial, 1924 pp. 7 y 8 , elaboración propia.

(47) Presupuestos... 1919, 1922-23, 1923-24, 1924-25..., op. cit., elaboración propia 


\section{b) La Hacienda segoviana de 1925 a 1931}

Las Haciendas Provinciales reguladas en el Libro II del Estatuto Provincial, del que se sentiría orgulloso su redactor, al conseguir sacar de la ruina a la mayoría de las Diputaciones. El contingente provincial fue reformado y reducido, por lo que perdió su carácter de principal fuente presupuestaria de ingresos, mientras que la facultad impositiva provincial fue reforzada al modificarse los arbitrios provinciales y añadir los impuestos y recursos cedidos por el Estado. En virtud del artículo 225, las Diputaciones recibirían el 5 por 100 de las cuotas de la contribución territorial, y en la misma sección se encontraba atribuido a las Corporaciones provinciales la percepción del Impuesto de cédulas personales.

También se preveía (arts. 228 y 229) que en caso de traspaso a las Diputaciones de obras públicas, establecimientos de Beneficencia, Sanidad e Instrucción Pública, se dotaría, por parte del Estado, el régimen de compensación económica correspondiente. Otros conceptos de interés fueron los recargos provinciales, entre ellos con carácter fijo, el 20 por 100 sobre las cuotas del Impuesto de Derechos Reales y el 10 por 100 sobre el Impuesto del Timbre, reconociendo la posibilidad de recargos del 100 por 100 en los arbitrios municipales sobre solares sin edificar y terrenos incultos. Finalmente, en virtud de la DT 10, fueron condonados los débitos de las Diputaciones a favor del Estado.

Como era de esperar, a partir de ese momento, la situación de la Hacienda Provincial de Segovia, mejoró notablemente, y así lo expresan los Presupuestos de los años 1926 a 1931, de acuerdo con el siguiente cuadro:

\section{PRESUPUESTOS DE LA DIPUTACION DE SEGOVIA 1926-1931}

\begin{tabular}{cc|c|c|c}
\hline \multicolumn{2}{c|}{ Años } & Ingresos & Gastos & Superávit \\
\hline 1926 & $\ldots \ldots$ & $3.242 .697,84$ & $2.455 .300,00$ & $787.397,00$ \\
1927 & $\ldots \ldots$ & $4.229 .050,38$ & $3.143 .905,76$ & $1.085 .145,22$ \\
1928 & $\ldots \ldots$ & $4.202 .417,62$ & $3.381 .901,65$ & $820.515,97$ \\
1929 & $\ldots \ldots$ & $3.726 .475,74$ & $2.701 .041,82$ & $1.025 .433,92$ \\
1930 & $\ldots$ & $3.764 .491,84$ & $2.907 .188,75$ & $857.303,09$ \\
1931 & $\ldots \ldots$ & $3.050 .379,73$ & $2.889 .304,31$ & $1.061 .075,40(48)$ \\
\hline
\end{tabular}

(48) Véanse Presupuestos provinciales. Años 1926, 1927, 1928, 1930, 1931. Segovia, Diputación Provincial, elaboración propia. 
- La estructura del Presupuesto provincial se modificó completamente en 1925. En principio se prorrogó el de 1924 para el primer semestre y antes del 30 de junio las Corporaciones tuvieron que elaborar un presupuesto nuevo a efectos del segundo semestre del año, pero las instrucciones recibidas en los últimos días de junio, supusieron en realidad, la continuidad hasta el 31 de diciembre de 1925 del presupuesto en vigor.

La distribución de los nuevos presupuestos constaba de 19 capítulos (Ingresos/Gastos), de acuerdo con la referencia que se expone seguidamente referida a 1927, que incluye el porcentaje sobre el total del capítulo correspondiente:

\begin{tabular}{|c|c|c|c|}
\hline \multicolumn{2}{|l|}{ INGRESOS } & \multicolumn{2}{|l|}{ GASTOS } \\
\hline \multirow{6}{*}{$\begin{array}{l}\text { Rentas } \ldots \ldots \ldots \ldots \ldots \\
\text { Bienes Provinciales } \ldots \ldots \ldots \\
\text { Subvenciones } \ldots \ldots \ldots \ldots \\
\text { Legados y Mandas } \ldots \ldots \ldots \\
\text { Eventuales } \ldots \ldots \ldots \ldots \ldots\end{array}$} & Porcentaje & \multirow{11}{*}{ 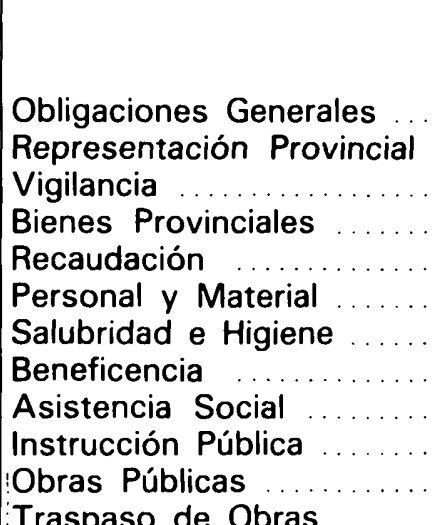 } & Porcentaje \\
\hline & 0.67 & & \multirow{13}{*}{$\begin{array}{c}2,43 \\
0,65 \\
0,04 \\
0,58 \\
1,30 \\
9,68 \\
0,47 \\
14,82 \\
0,04 \\
3,57 \\
36,41 \\
- \\
- \\
1,11 \\
-\end{array}$} \\
\hline & 0,01 & & \\
\hline & 8,42 & & \\
\hline & - & & \\
\hline & 0,03 & & \\
\hline $\begin{array}{l}\text { Contribuciones Especiales } \\
\text { Derechos y Tasas }\end{array}$ & & & \\
\hline Arbitrios Provinciales .... & 3,54 & & \\
\hline Impuestos cedidos Estado & 10,43 & & \\
\hline $\begin{array}{l}\text { Cesión Recursos Municipa- } \\
\text { les } \ldots \ldots \ldots \ldots \ldots \ldots \ldots\end{array}$ & 20,73 & & \\
\hline Recargos Provinciales & 5,57 & & \\
\hline Traspaso de Obras & - & Montes y Pesca & \\
\hline Crédito Provincial ... & - & ${ }_{G} G a n a d e r i ́ a \quad . . . .$. & \\
\hline Recursos Especiales & 1,45 & Crédito Provincial & \\
\hline Multas ................... & - & 'Mancomunidades Provin- & \\
\hline $\begin{array}{l}\text { Mancomunidades Provincia- } \\
\text { les } \ldots \ldots \ldots \ldots\end{array}$ & & $\begin{array}{l}\text { ciales } \ldots \ldots \ldots \ldots \ldots \ldots \\
\text { Devoluciones } \ldots \ldots \ldots \ldots \ldots\end{array}$ & $\overline{0,03}$ \\
\hline Reintegros & 0,73 & Imprevistos & 0,31 \\
\hline Fianzas & & Resultas (49) & 28,56 \\
\hline Resultas . & 43,35 & & \\
\hline
\end{tabular}

Las modificaciones presupuestarias resultaban bastante amplias respecto a la situación anterior, pues vemos que las Cesiones de Recursos Municipales bajan al 20,73 por 100 , frente al 41,08 por 100 de 1924, apareciendo nuevos capítulos como Subvenciones,

(49) Véase Presupuesto refundido para el año 1927. Segovia. Diputación Provincial, 1927. pp. 5 a 14 . 
Impuestos cedidos por el Estado, Arbitrios Provinciales y Recargos Provinciales que supusieron, en conjunto, el 27,96 por 100 de los ingresos, lo que unido al 48,35 por 100 de las resultas hacía insignificante el 2,96 por 100 del resto de los capítulos. Esta estructura presupuestaria se mantuvo a lo largo de todo el período con ligeras oscilaciones.

Respecto del Presupuesto de Gastos disminuía el porcentaje total en los servicios de Beneficencia, aunque el aumento cuantitativo referido a 1924 fue de: 20.088 en $1927,85.088$ en 1928 , 77.463 en $1929,118.909$ en 1930 y 72.113 en 1931 (50).

Sin embargo, el incremento más notable corresponde al capitulo de Obras Públicas que comprendía la construcción, reparación y conservación de carreteras provinciales y caminos vecinales, el establecimíento de líneas telegráficas, construcción y explotación de ferrocarriles y la construcción, reparación y conservación de edificios provinciales.

Desde 1927 a 1931 el porcentaje del capítulo de Obras Públicas sobre el total presupuestario de gastos fue:

Año 1927: 36,41 por 100.
Año 1928: 30,89 por 100.
Año 1929: 28,77 por 100.
Año 1930: 24,61 por 100.
Año 1931: 24,44 por 100 (51).

Otro capítulo que aumentó fue el de Personal y Material. En 1924 era de 92.106 pesetas y en 1927 de 283.410, situación a la que, sin duda, influyó decisivamente la propuesta de la Memoria elevada al Directorio sobre el particular.

Esta fue, en líneas generales, la situación de la Hacienda Provincial de la Diputación de Segovia para el período 1920-1931. $\mathrm{Si}$ en la primera época la situación fue bastante saneada y aceptable, a partir de 1926 experimentó un crecimiento importante merced a la nueva generación de recursos amparada por el Estatuto Provincial.

(50) Véase Presupuestos provinciales..., op. cit., elaboración propia.

(51) Ibidem, 1927-1931, elaboración propia. 